\title{
Determination Permeability Coefficient from Piezocone
}

\author{
Qiang Wang' and LiYuan Tong ${ }^{2}$ \\ ${ }^{1}$ Department of Civil Engineering, Anhui University of Science and Technology, Huainan Anhui 232001, China \\ ${ }^{2}$ Institute of Geotechnical Engineering, Southeast University, Nanjing, Jiangsu 210096, China \\ Correspondence should be addressed to Qiang Wang; wangqiang0711@163.com
}

Received 8 January 2014; Accepted 27 March 2014; Published 27 April 2014

Academic Editor: John W. Gillespie

Copyright (C) 2014 Q. Wang and L. Tong. This is an open access article distributed under the Creative Commons Attribution License, which permits unrestricted use, distribution, and reproduction in any medium, provided the original work is properly cited.

\begin{abstract}
The permeability coefficient of soil profile is one of the problems concerned by engineers, and the determination of permeability coefficient method mainly relies on the laboratory permeability test and field pumping test, but these tests are time-consuming and inefficient, and especially the permeability coefficient of soil under the condition of partial drainage was difficult to determine; in this paper, the modern digital CPTU technology was used. Dimensional permeability $K_{T}$ was defined by using the dimensionless normalized cone tip resistance $Q_{t}$, friction factor $F_{r}$, and pore pressure ratio $B_{q}$, these parameters enable plots of $B_{q}-Q_{t}, F_{r}-Q_{t}, B_{q}-F_{r}$ to be contoured $K_{T}$ and hence for permeability coefficient. The relationship has been applied to Nanjing 4th Yangtze river bridge, and compared with laboratory penetration test. The results indicate that the method can accurately determine the permeability coefficient of soil under partial drainage condition and provide the theoretical basis for engineering application.
\end{abstract}

\section{Introduction}

With the development of foundation pit engineering to larger and deeper and the surrounding environment is increasingly complex, especially in the city downtown area, some excavations close to the high-rise buildings, some excavations close to the subway tunnel. At the same time, the groundwater treatment around the excavation cannot be avoided, and the environmental problems around the excavation caused by dewatering are becoming more and more serious. How to arrange dewatering to reduce the impact as much as possible is the key issue for many scholars and technicians. In order to reasonably arrange the dewatering well, we must grasp permeability characteristics of each soil accurately. The key parameter of permeability characteristics is the permeability coefficient. The permeability coefficient is the relative strength index of soil. It is a basic parameter and it must be used for seepage calculation; therefore, the accurate determination of soil permeability coefficient is a very important work, and it plays an important role in the success of the excavation. The current methods for determining the permeability coefficient are routine laboratory permeability test, field pumping test, water pressure test, and so forth. Routine laboratory permeability test is divided into constant head permeability test and variable head permeability test. The laboratory permeability test is widely used, mainly because of its easy operation and simple equipment; however, it has some disadvantages: (1) soil disturbance, (2) inaccurate permeability test, especially sand inclusion or interbed, (3) not simulating field boundary conditions, and (4) the heavy workload and high cost. These drawbacks make much difference for the permeability coefficient between field test and laboratory test.

Piezocone penetration test (CPTU) is a time-saving, little disturbance, convenient and economic method for permeability coefficient of soil. The permeability coefficient of the soil was able to relatively accurately obtain, especially mixed-layer or thin interbed experts and scholars at home and abroad dedicated to the study method that can accurately determine the permeability coefficient.

\section{Methods}

Since the advent of multifunction, a lot of the relationships between permeability coefficient and multifunctional CPTU parameters have been proposed. The main methods of permeability coefficient of cohesive soil are divided into 


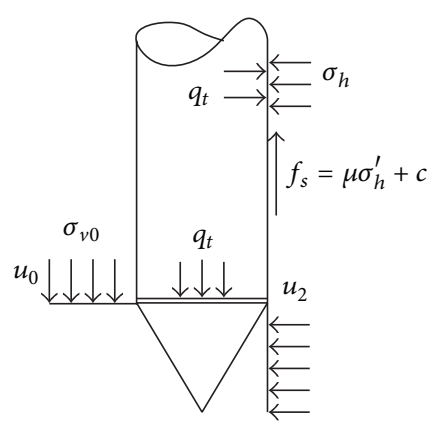

FIGURE 1: Tip local conditions. Cone expansion stress is $q_{t}$.

two categories: (1) to estimate permeability coefficient based on the soil classification and (2) to estimate permeability coefficient based on the pore pressure dissipation test. The correct tip resistance $q_{t}$, pore pressure ratio $B_{q}$ and sleeve friction $f_{s}$ were modified to determine the type of soil [1-3] and (Olsen [4]). The permeability coefficient was estimated from soil classification [5]. And by the pore pressure ratio $B_{q}$ [6] and by the side friction $f_{s}$ to determinate the permeability coefficient of soil, the coefficient of permeability coefficient was directly determined by using the cone tip resistance and side friction $[7,8]$.

View of the calculation of consolidation coefficient is less than $7.1 \times 10^{-5} \mathrm{~m} / \mathrm{s}^{2}$, the consolidation coefficient of the cohesive soil can be determined by the pore pressure dissipation in the completely undrained condition, and then the permeability coefficient can be determined by the consolidation coefficient according to the relationship between permeability coefficient and consolidation coefficient. However, the consolidation coefficient between $7.1 \times 10^{-5} \mathrm{~m} / \mathrm{s}^{2}$ and $1.4 \times$ $10^{-2} \mathrm{~m} / \mathrm{s}^{2}$ was taken for the part of drainage condition, so the pressure dissipation was not used. The partial drainage state boundary range $B_{q} Q_{t}<1.2 Q_{t} F_{r}<0.3 B_{q} / F_{r}<4$ was proposed. Based on the partial drainage condition given by Elswroth [9], the permeability coefficient was put forward to determine by using CPTU data.

2.1. Cavity Expansion Theory. For the saturated clay under undrained conditions, cylindrical cavity expansion stress was proposed by using [10]

$$
\sigma_{r}=\sigma_{v 0}+\frac{4}{3} S_{u}\left[1+\ln \left(\frac{G}{S_{u}}\right)\right],
$$

where $G$ is shear modulus, $G=E / 2(1+\mu), \mu$ is Poisson's ratio, $E$ is elastic modulus, $S_{u}$ is undrained shear strength, $\mathrm{kPa}$, and $\sigma_{v 0}$ is overburden stress, $\mathrm{kPa}$.

Under undrained conditions, the excess pore pressure caused by cavity expansion can be calculated using the average total stress increment $\Delta \sigma_{m}$

$$
\Delta u=u_{2}-u_{0}=\Delta \sigma_{m}=\frac{1}{3}\left(\Delta \sigma_{r}+2 \Delta \sigma_{\theta}\right)=\frac{4}{3} S_{u} \ln \left(\frac{G}{S_{u}}\right),
$$

where $u_{2}$ is cone shoulder pressure, $u_{0}$ is hydrostatic pressure, and $q_{t}$ is the correct cone tip resistance.
In the CPTU penetration process, the horizontal stress is assumed to be equal to the cavity expansion stress. For the cohesionless soil $c=0$, the normalized friction ratio $F_{r}$ and pore pressure were established relationships, and noticed the sleeve friction, $f_{s}=\mu \sigma_{h}^{\prime}, \sigma_{h}^{\prime}=\sigma_{h}-u_{2}, c, \varphi$ were the soil strength parameters. The friction factor is assumed to be $\mu=$ $\tan \varphi$ as shown in Figure 1

$$
f_{s}=\left(\sigma_{h}-u_{2}\right) \times \tan \phi .
$$

2.2. Dimensionless Parameters. CPTU sounding yields profiles of the correct tip cone resistance, $q_{t}$, cone shoulder pore pressures, $u_{2}$, and sleeve friction, $f_{s}$, with depth. These dimensional metrics may be defined as normalized magnitudes of tip resistance, $Q_{t}$, pore pressure ratio, $B_{q}$, and friction ratio, $F_{r}$, as

$$
\begin{aligned}
& Q_{t}=\frac{q_{t}-\sigma_{v 0}}{\sigma_{v 0^{\prime}}^{\prime}}, \\
& B_{q}=\frac{u_{2}-u_{0}}{q_{t}-\sigma_{v 0}}, \\
& F_{r}=\frac{f_{s}}{q_{t}-\sigma_{v 0}},
\end{aligned}
$$

where $\sigma_{v 0}^{\prime}$ is the effective overburden stress, $\mathrm{kPa}, u_{0}$ is hydrostatic pressure, $\mathrm{kPa}$, and $u_{2}$ is cone shoulder pressure, $\mathrm{kPa}$.

If the adhesion of the cone sleeve is assumed to be equal to the undrained shear strength, $f_{s}=S_{u}$, then the magnitudes of nondimensional cone metrics of end-bearing, sleeve friction, and pore pressure ratio may be determined by substituting (1) and (2) into (4) to yield

$$
\begin{gathered}
B_{q}=\frac{u_{2}-u_{0}}{q_{t}-\sigma_{v 0}}=\frac{\ln \left(G / S_{u}\right)}{1+\ln \left(G / S_{u}\right)} \\
Q_{t}=\frac{q_{t}-\sigma_{v 0}}{\sigma_{v 0}^{\prime}}=\frac{4 S_{u}}{3 \sigma_{v 0}^{\prime}}\left[1+\ln \left(\frac{G}{S_{u}}\right)\right] \\
F_{r}=\frac{f_{s}}{q_{t}-\sigma_{v 0}}=\tan \phi\left(1+\frac{1}{Q_{t}}-B_{q}\right) \\
B_{q} Q_{t}=\frac{u_{2}-u_{0}}{q_{t}-\sigma_{v 0}} \cdot \frac{q_{t}-\sigma_{v 0}}{\sigma_{v 0}^{\prime}}=\frac{4 S_{u}}{3 \sigma_{v 0}^{\prime}} \ln \left(\frac{G}{S_{u}}\right) .
\end{gathered}
$$




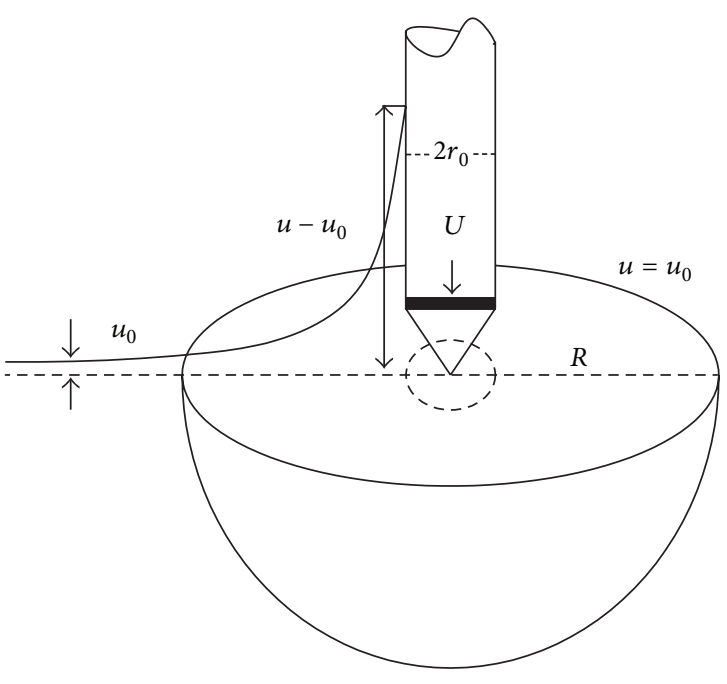

(a)

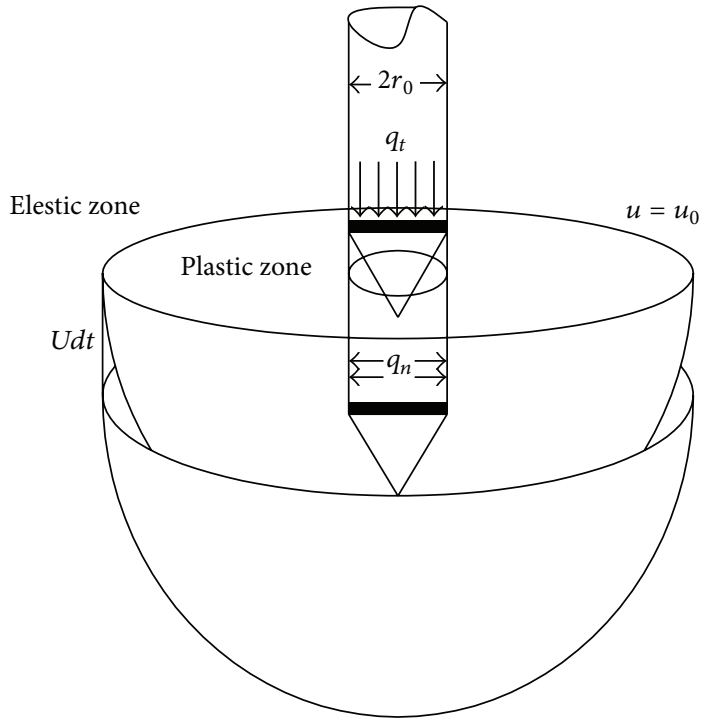

(b)

FIGURE 2: Geometry of process zone surrounding advancing penetrometer.

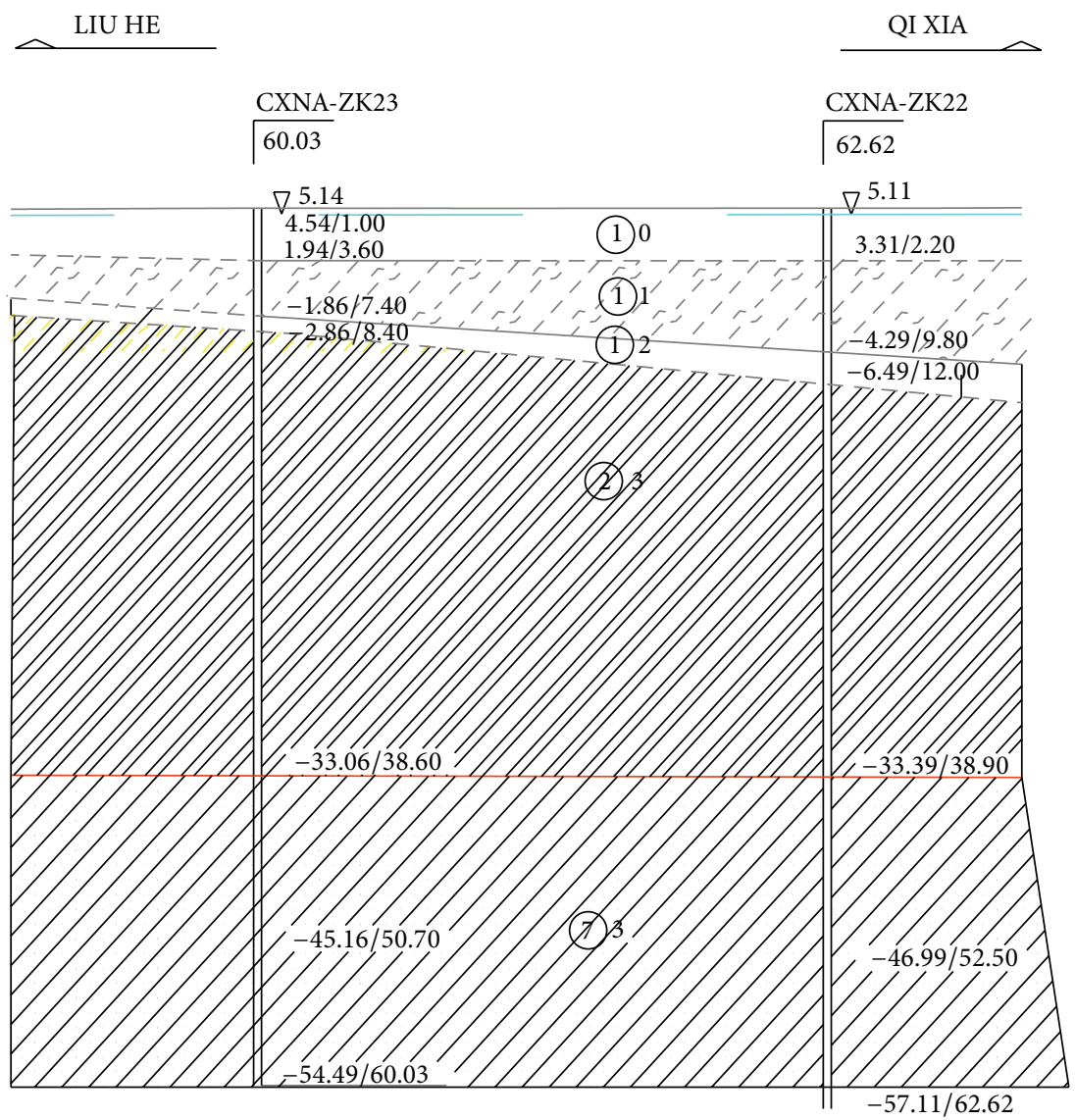

FIGURE 3: The soil profile of north anchorage of the Yangtze river 4 th bridge $\left(1_{0}=\right.$ Clay, $1_{1}=$ silty clay, $\left(1_{2}=\right.$ silt, $(2)=$ silty clay with fine sand interbed, $7_{3}=$ bedrock. 


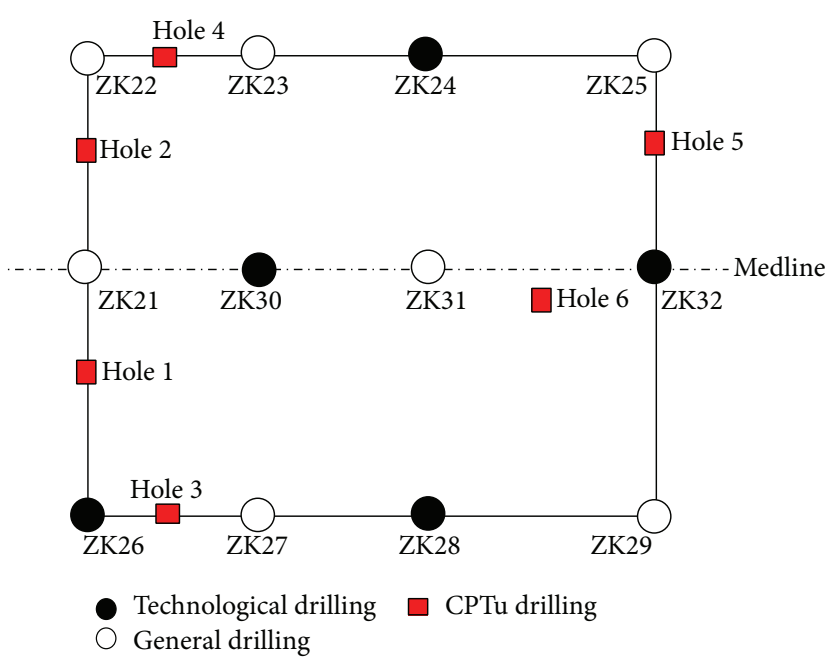

FIgURE 4: Layout diagram of CPTu holes in Yangtze River four bridge north anchorage.

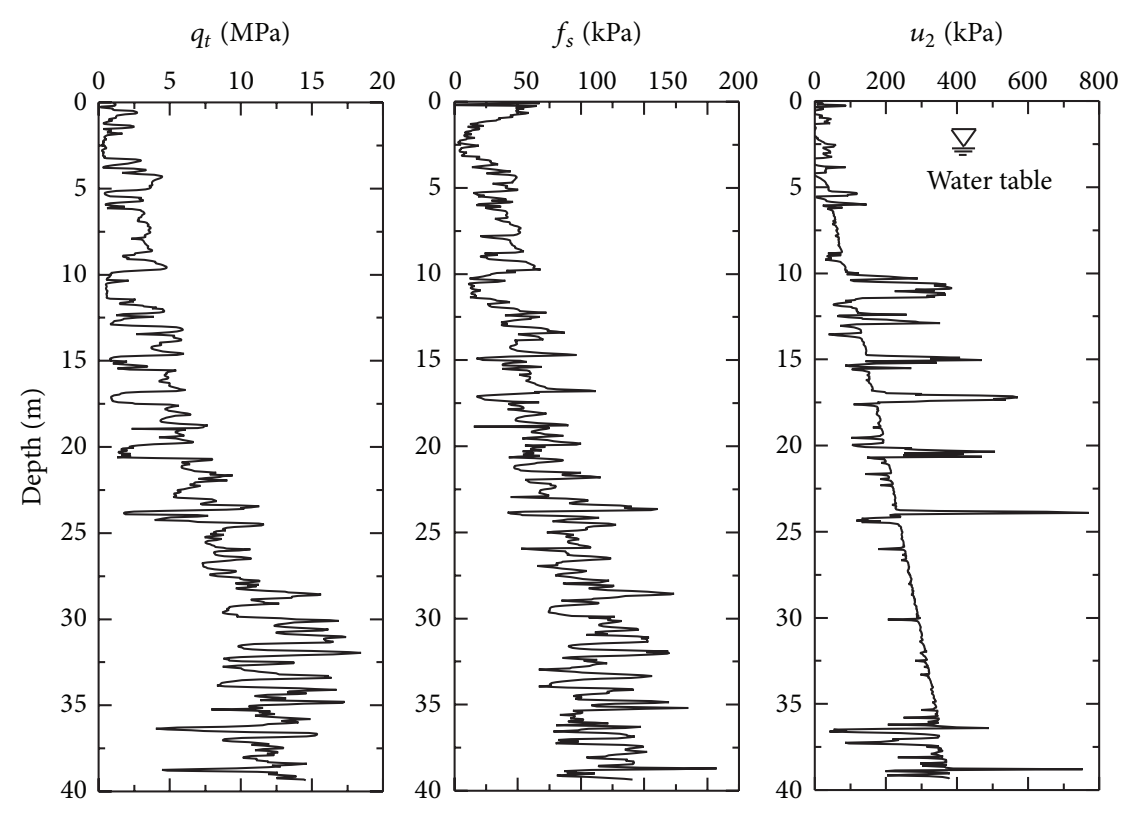

Figure 5: Results of CPTu.

It is assumed that the penetration of a standard cone has a stable speed (i.e., $20 \mathrm{~mm} / \mathrm{s}$ ). According to the fluid continuity theorem and the Darcy law, the water volume is equal to the cone penetration volume in unit time, as shown in (9) and $u_{r}$ is the hydrostatic pressure where $r=r_{h}$ it is assumed that the permeability coefficient has a small variation in the penetration process. At the same time, when $r_{h} \rightarrow \infty$ and $r_{0} / r_{h} \rightarrow 0$, the pore pressure is hydrostatic pressure $u_{0}$, namely, (10) calculation diagram as shown in Figure 2. Consider

$$
\begin{gathered}
u_{2}-u_{r}=\frac{\gamma_{w}}{4 \pi K_{h} r_{0}}\left(1-\frac{r_{0}}{r_{h}}\right) d V=\frac{U r_{0} \gamma_{w}}{4 K_{h}}\left(1-\frac{r_{0}}{r_{h}}\right) \\
u_{2}-u_{0}=\frac{\gamma_{w}}{4 \pi K_{h} r_{0}} d V=\frac{U r_{0} \gamma_{w}}{4 K_{h}} .
\end{gathered}
$$

Take into consideration

$$
B_{q} Q_{t}=\frac{u_{2}-u_{0}}{q_{t}-\sigma_{v 0}} \cdot \frac{q_{t}-\sigma_{v 0}}{\sigma_{v 0}^{\prime}}=\frac{u_{2}-u_{0}}{\sigma_{v 0}^{\prime}},
$$

and assumption that

$$
B_{q} Q_{t}=\frac{1}{K_{T}}
$$

Obtain

$$
K_{h}=\frac{U r_{0} \gamma_{w} \cdot K_{T}}{4 \cdot \sigma_{v 0}^{\prime}}
$$

where $U$ is penetration rate of $\mathrm{m} / \mathrm{s} ; r_{0}$ is cone radius $\mathrm{m} ; K_{T}$ is the dimensionless permeability index; $K_{h}$ is permeability coefficient, $\mathrm{m} / \mathrm{s}$. 


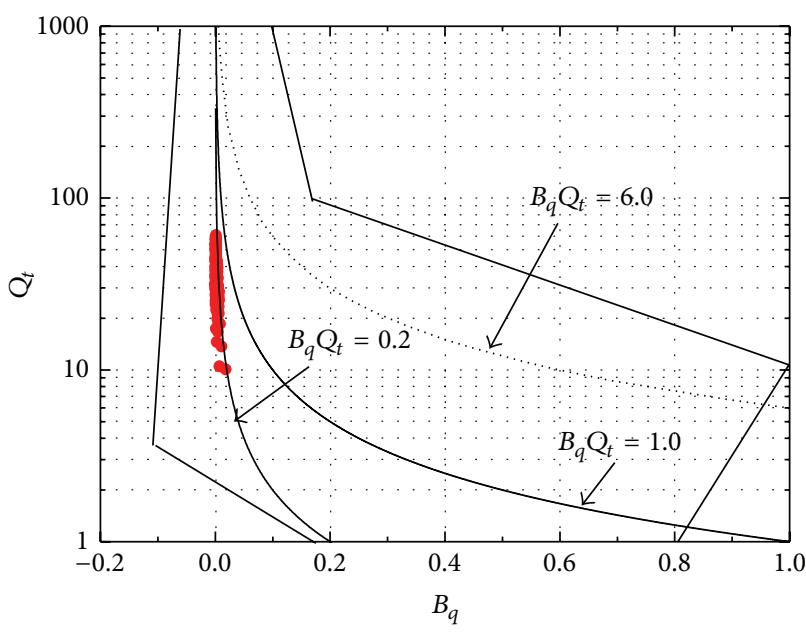

(a)

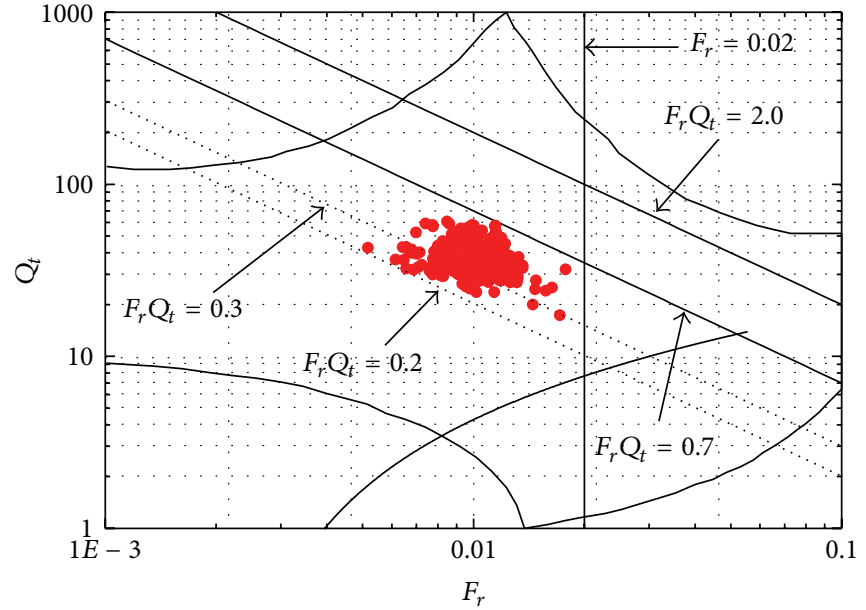

(b)

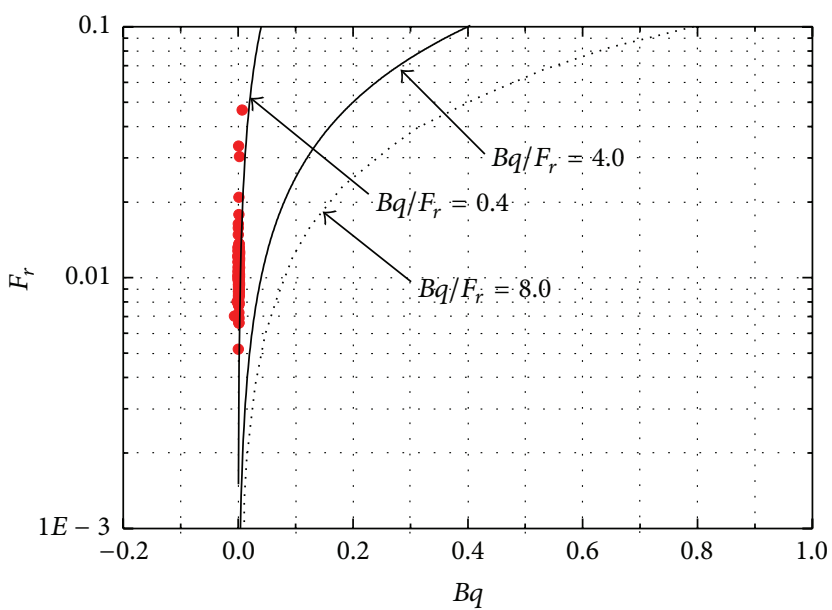

(c)

FIGURE 6: Contoured plots of $B_{q}-Q_{t}, F_{r}-Q_{t}$, and $B_{q}-F_{r}$.

Substitute $B_{q}=1 / Q_{t} K_{T}$ into (7)

$$
\begin{gathered}
K_{T}=\frac{1}{B_{q}}\left(\frac{F_{r}}{\tan \phi}-1+B_{q}\right), \\
K_{T}=\frac{1}{Q_{t}\left(1+1 / Q_{t}-F_{r} / \tan \phi\right)},
\end{gathered}
$$

where $B_{q}$ is the pore pressure ratio, $Q_{t}$ is the normalized tip resistance, $F_{r}$ is resistance ratio, $K_{T}$ is the dimensionless permeability index, and $K_{h}$ is the permeability coefficient, $\mathrm{m} / \mathrm{s}$.

Equation (14) showed that the friction ratio $F_{r}$ and pore pressure ratio $B_{q}$ can calculate the dimensionless permeability index $K_{T}$. Equation (15) shows that $K_{T}$ can be calculated by the frictional ratio $F_{r}$ and the normalized tip resistance $Q_{t}$. According to $k_{h}=U r_{0} \gamma_{w} \cdot K_{T} / 4 \cdot \sigma_{v 0}^{\prime}$, the soil permeability coefficient can be calculated in partially drained conditions by using the obtained $K_{T}$ values.

\section{Engineering Examples}

3.1. Engineering Overview. South and North Anchorage of the 4th Nanjing Yangtze River Bridge are located in the Yangtze River levee on both sides of south and North, belonging to the lower reaches of the Yangtze River alluvial floodplain. The site of north anchor of the 4th Nanjing Yangtze River Bridg is located in Nanjing fine mag Technology Co. Ltd. factory area, the ground elevation is about $5.5 \sim 6.1 \mathrm{~m}$. The northern boundary of south anchor is apart from dyke and river more than 60 meters and 200 meters respectively. The north anchorage ground elevation is about $4.5 \sim 5.2 \mathrm{~m}$, the site and the surrounding for forest, the southern boundary of north anchor is apart from the dyke and river about $120 \mathrm{~m}$ and $120 \mathrm{~m}$ respectively. The Quaternary loose sediment thickness is more than $60 \mathrm{~m}$ in north anchor.

3.2. Results of CPTU Test. From June 17, 2007, to June 23, 2007, the CPTU tests (six holes) were carried out in north anchor of Nanjing 4th Yangtze River Bridge. The soil profile of north anchorage of the Yangtze river 4th bridge is shown in Figure 3. 
TABLE 1: Estimated soil permeability $(k)$ based on normalized CPT soil behavior type (SBTn) by Robertson [2] (modified from Lunne et al., $[11])$.

\begin{tabular}{lccc}
\hline SBTn zone & SBTn & Range of $k(\mathrm{~m} / \mathrm{s})$ & $I_{c}$ \\
\hline 1 & Sensitive fine grained & $3 \times 10^{-10}$ to $3 \times 10^{-8}$ & $\mathrm{NA}$ \\
2 & Organic soils clay & $1 \times 10^{-10}$ to $1 \times 10^{-8}$ & $2.95<I_{c}<3.60$ \\
3 & Clay & $1 \times 10^{-9}$ to $1 \times 10^{-9}$ & $2.60<I_{c}<2.95$ \\
4 & Silt mixture & $3 \times 10^{-9}$ to $1 \times 10^{-7}$ & $2.05<I_{c}<2.60$ \\
5 & Sand mixture & $1 \times 10^{-7}$ to $1 \times 10^{-5}$ & $1.31<I_{c}<2.05$ \\
6 & Sand & $1 \times 10^{-5}$ to $1 \times 10^{-3}$ & $I_{c}<1.31$ \\
7 & Dense sand gravelly sand & $1 \times 10^{-3}$ to 1 & $\mathrm{NA}$ \\
8 & Very dense/stiff soil & \\
9 & Very stiff fine-grained soil $^{*}$ & $1 \times 10^{-8}$ to $3 \times 10^{-5}$ & $\mathrm{NA}$ \\
\hline
\end{tabular}

${ }^{*}$ Overconsolidated and/or cemented.

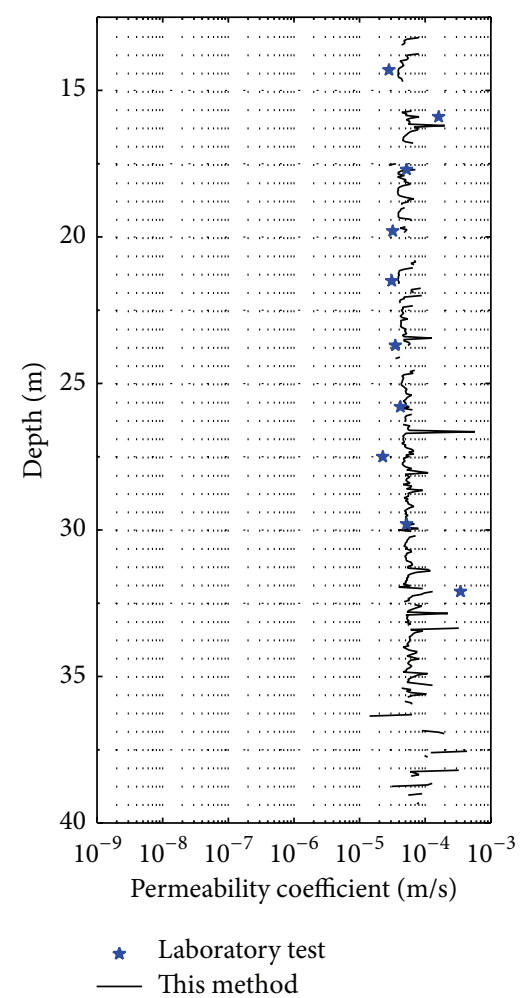

Figure 7: Curve of permeability coefficient changing with depth.

The hole position is shown in Figure 4. The CPTU test results were as shown in Figure 5. From Figure 6, it can be seen that the measuring points of the sand layer are located in the range of $0<B_{q} Q_{t}<0.2, Q_{t} F_{r}<0.2 \sim 0.7, B_{q} / F_{r}<4, F_{r}<0.2$, which belongs to the section of the partial drainage conditions, so it can calculate the soil permeability coefficient according to (12) (15).

Based on laboratory tests, the internal friction angle of slit is $30.9^{\circ}$, and the internal friction angle of fine sand is $32.5^{\circ}$ and the internal friction angle of silty soil is $31^{\circ}$. The permeability coefficient related to the depth can be calculated by the equation (13). Figure 7 shows the comparison between the calculated results and the laboratory test ones, shown in
Figure 7. As seen from Figure 6, the permeability coefficients from the laboratory test and the CPTU test were consistent and the trend is basically same. The permeability coefficient using the presented method to calculate was in accordance with the scope of permeability coefficient in Table 1 [2].

\section{Conclusion}

The dimensionless penetration index $K_{T}$ was derived through the normalized tip resistance $Q_{t}$, frictional ratio $F_{r}$, and the pore pressure ratio $B_{q}$ relationship in partial drainage conditions; based on $K_{T}$, the permeability coefficient can be calculated. Comparing the results of laboratory test and the CPTU test, we can see the permeability coefficient in the range of $10^{-4} \mathrm{~m} / \mathrm{s}-10^{-7} \mathrm{~m} / \mathrm{s}$ from the test results of soil under partially drained conditions and more than $10^{-4} \mathrm{~m} / \mathrm{s}$ in complete drainage conditions and less than $10^{-7} \mathrm{~m} / \mathrm{s}$ in undrained condition the permeability coefficient can be calculated through the pore pressure dissipation test.

The engineering application shows that the permeability coefficients obtained from the pumping test and CPTU test are identical. This method can provide the reference for practical foundation pit dewatering.

\section{Conflict of Interests}

The authors declare that there is no conflict of interests regarding the publication of this paper.

\section{Acknowledgments}

The work described in this paper was supported by the Outstanding Youth Fund of the Education Department of Anhui Province (Project no. 2011SQRL045), Master/Doctor Fund of the Anhui University of Science and Technology, Young Scholar Fund of the Anhui University of Science and Technology, and the National Natural Science Foundation of China (Project no. 51208005). 


\section{References}

[1] Douglas, B. J, Olsen, and R. S, "Soil classification using electric cone penetrometer. Cone penetration testing and experience," in Proceedings of the ASCE National Convention (ASCE '81), pp. 209-227, New York, NY, USA, 1981.

[2] P. K. Robertson, "Soil classification using the cone penetration test," Canadian Geotechnical Journal, vol. 27, no. 1, pp. 151-158, 1990.

[3] P. K. Robertson and C. E. Wride, "Evaluating cyclic liquefaction potential using the cone penetration test," Canadian Geotechnical Journal, vol. 35, no. 3, pp. 442-459, 1998.

[4] R. S. Olsen and J. V. Farr, "Site characterization using the cone penetrometer test," in Use of in Situ Tests in Geotechnical Engineering, pp. 854-868, American Society of Civil Engineers (ASCE), New York, NY, USA, 1986.

[5] M. Manassero, "Hydraulic conductivity assessment of slurry wall using piezocone test," Journal of Geotechnical Engineering, vol. 120, no. 10, pp. 1725-1746, 1994.

[6] R. S. Olsen, "Normalization and prediction of geotechnical properties using the cone penetrometer test," Tech. Rep. GL-9429, U.S. Army Corps of Engineers, WES, Vicksburg, Miss, USA, 1994.

[7] J. M. Smythe, P. B. Bedient, R. A. Klopp, and C. Y. Chiang, "An advanced technology for the in situ measurement of heterogeneous aquifers," in Proceedings of the Conference on New Field Techniques for Quantifying the Physical and Chemical Properties of Heterogeneous Aquifer, pp. 605-628, 1989.

[8] C. Y. Chiang, K. R. Loos, and R. A. Klopp, "Field determination of geological/chemical properties of an aquifer by cone penetrometry and headspace analysis," Ground Water, vol. 30, no. 3, pp. 428-436, 1992.

[9] D. Elsworth and D. S. Lee, "Permeability determination from on-the-fly piezocone sounding," Journal of Geotechnical and Geoenvironmental Engineering, vol. 131, no. 5, pp. 643-653, 2005.

[10] R. Hill, The Mathematical Theory of Plasticity, Oxford University Press, Oxford, UK, 1983.

[11] T. Lunne, P. K. Robertson, and J. J. M. Powell, Cone Penetration Testing Geotechnical Practicem, Chapman and Hall, London, UK; Spon press Taylor \& Francis Group, New York, NY, USA, 1997. 

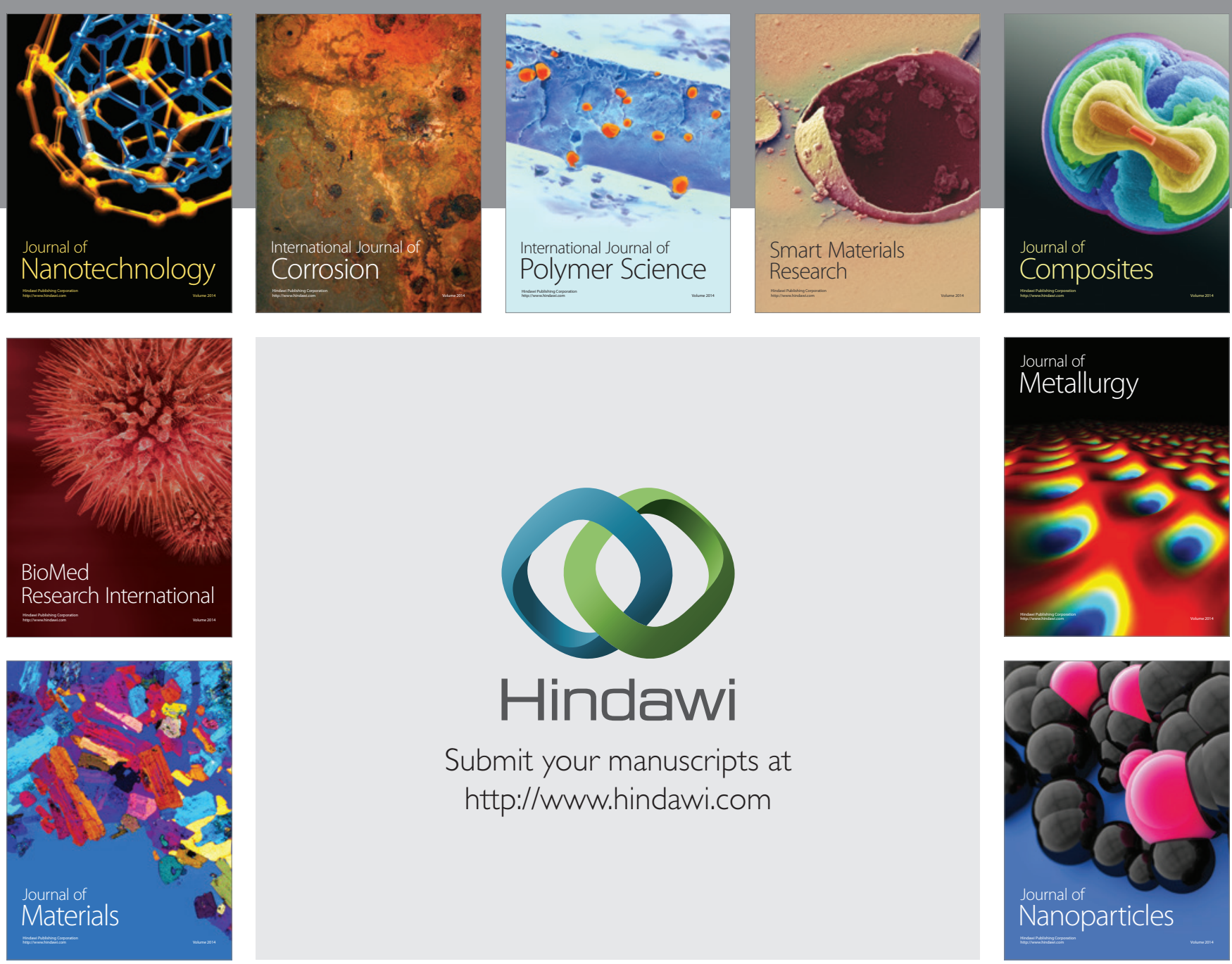

Submit your manuscripts at http://www.hindawi.com
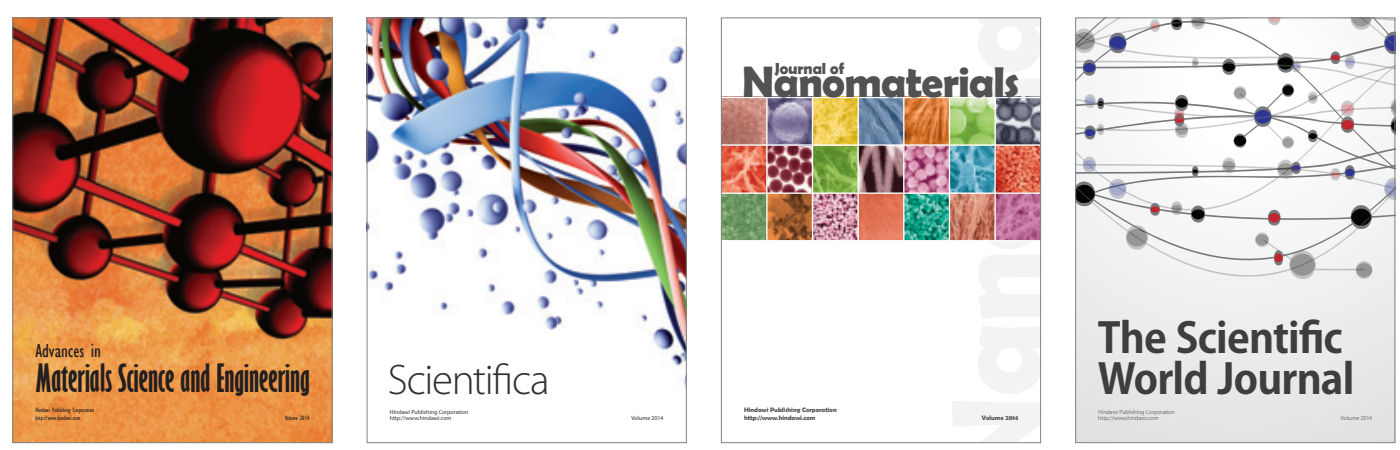

\section{The Scientific World Journal}
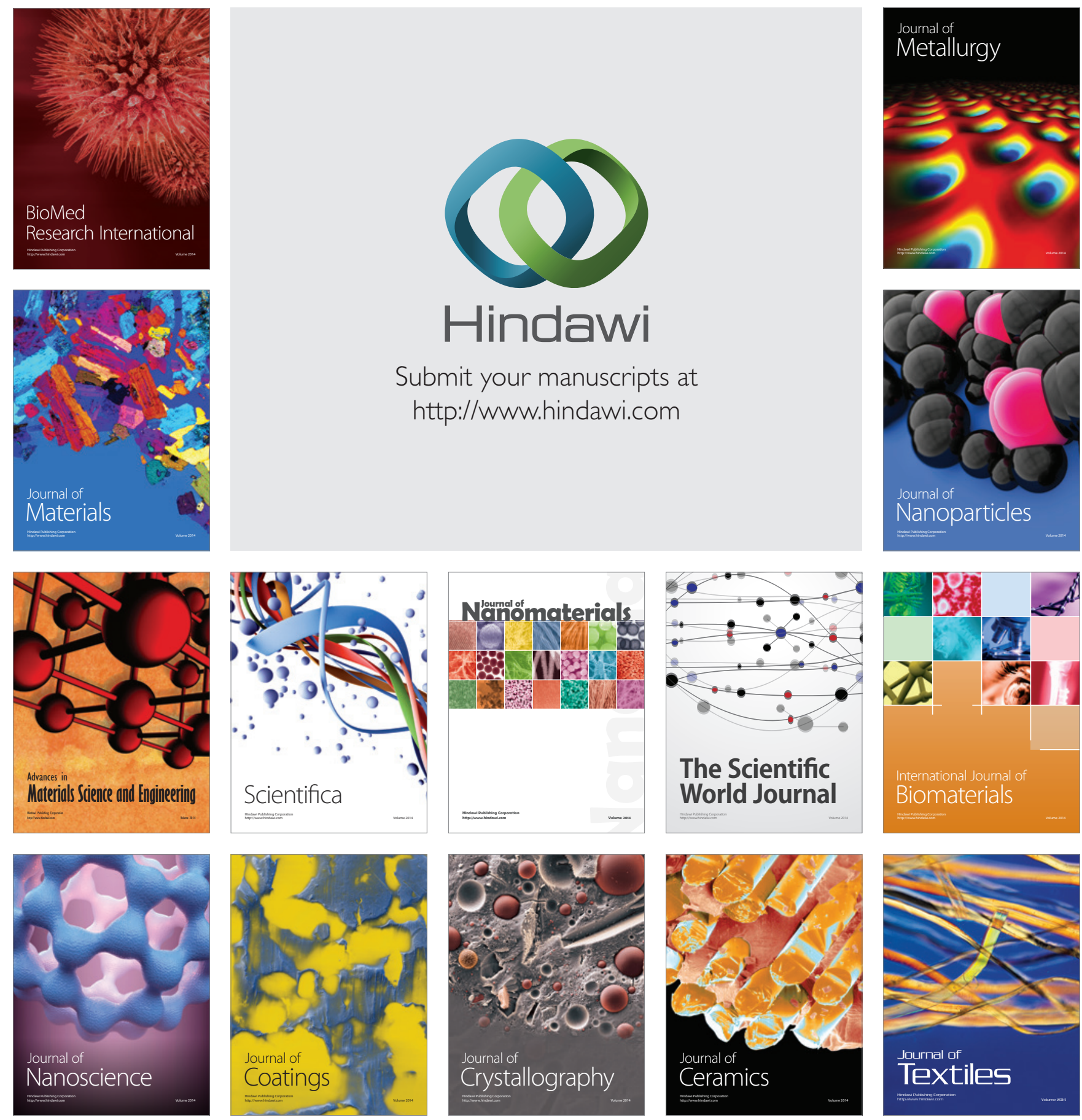